\title{
Analysis of Noise and Vibration on Single Cylinder Four Stroke Engine with Green Diesel Fuel Based on Simulations
}

\author{
Beny Cahyono ${ }^{1}$, Aguk Zuhdi M. Fathallah ${ }^{2}$, Muhammad Hadrian Deswandi J. ${ }^{3}$, Semin ${ }^{4}$ \\ (Received: 22 August 2020 / Revised: 16 March 2021 / Accepted: 17 March 2021)
}

\begin{abstract}
Despite the fact that both use the same raw material, vegetable oil, the processes for producing green diesel and biodiesel are somewhat different. Green diesel is generated via the hydrotreating process, which involves injecting hydrogen gas into an oil to remove oxygen. The combustion process in the engine is influenced by the nature of the fuel. Green diesel fuel has a higher yield of material than biodiesel fuel. High pressure caused by combustion in the engine combustion chamber affects the vibrations and noises of diesel engines. By varying engine speed and load, this study compares noise and vibration produced by green diesel fuel to biodiesel $\mathrm{B30}$ using a simulation process. The results showed that green diesel fuel produces more noise and vibration than biodiesel $\mathrm{B3O}$ fuel and that this is directly proportional to the pressure and power produced in the combustion chamber by the green diesel fuel combustion process. As the pressure in the combustion chamber rises, the explosion becomes more powerful, resulting in increased diesel engine noise and vibration.
\end{abstract}

Keywords—diesel engine, green diesel, noise, vibration.

\section{INTRODUCTION}

A diesel engine is an internal combustion engine that uses compression to blow up the mixture of diesel fuel and air entering the combustion chamber. The use of this machine is very much in various fields, especially in the maritime sector, namely ships. Indonesia as an archipelagic country, of course, uses ships a lot as a mode of transportation to connect from island to island. The choice of the motor for driving is a diesel motor because diesel motors have better thermal efficiency and high torque. This machine is suitable for use on vehicles and heavy equipment. The fuel used in this machine is diesel or diesel oil which is generally processed from the distillation of the petroleum fraction.

Since Rudolph Diesel discovered the diesel engine in 1987, diesel oil has been widely used for the needs of the transportation sector. This contributes significantly to environmental pollution and climate change caused by $\mathrm{CO}_{2}$ emissions. The European Union has set a near-zero environmental footprint target by 2020 as the efforts to reduce the impact of global transactions and towards energy independence. Biomass and biofuels derived from biomass such as green gasoline biodiesel, biogas, bio-hydrogen, bio-methane, bio-ethanol, and green diesel are several alternatives that can reduce $\mathrm{CO} 2$ levels in the atmosphere and replace fossil fuels [1].

Beny Cahyono is with Departement of Marine Engineering, Institut Teknologi Sepuluh Nopember, Surabaya, 60111, Indonesia. E-mail: benyjtsp98@gmail.com

Aguk Zuhdi M. Fathallah is with Departement of Marine Engineering, Institut Teknologi Sepuluh Nopember, Surabaya, 60111, Indonesia. E-mail: fathalaz@its.ac.id

Muhammad Hadrian Deswandi J. is with Departement of Marine Engineering, Institut Teknologi Sepuluh Nopember, Surabaya, 60111, Indonesia. E-mail: muhammadhadrian@yahoo.com

Semin is with Department of Marine Engineering, Institut Teknologi Sepuluh Nopember, Surabaya, 60111, Indonesia. E-mail: semin@its.ac.id
The Indonesian government has recently conducted research on green diesel in collaboration with PT Pertamina to reduce imports of diesel fuel (BBM). According to data from the Central Statistics Agency (BPS), oil and gas imports for the period January to August 2018 were at $\$ 15.41$ billion. According to Arcandra Tahar (Deputy Minister of Energy and Mineral Resources), Green Diesel is of higher quality than biodiesel because of its lower sulfur content. In addition, fuels are not like Fatty Acid Methyl Ester (FAME) which can cause corrosion.

In previous research conducted [1], green diesel fuel has a much higher CN, LHV, and $\mathrm{H} / \mathrm{C}$ atomic ratio than diesel oil. Several studies have examined green diesel in road vehicles and laboratory-scale internal combustion engines which provide information on combustion systems that provide up to $10 \%$ higher thermal information and 5-10\% lower SFOC.

Vibration and noise are very important problems of diesel engines, this is due to the combustion process that occurs in diesel engines. Part of the vibration and noise is caused by the engine and exhaust system. The vibrations that occur in the engine occur from the components that work in the engine. Vibration measurements are widely used to characterize combustion and monitor engine operating conditions. The pressure in the engine cylinders provides important information on parameters such as combustion, emissions, and performance in an internal combustion engine. The pressure in the cylinder chamber has an impact on the vibration and noise that occurs in the engine [2]. 


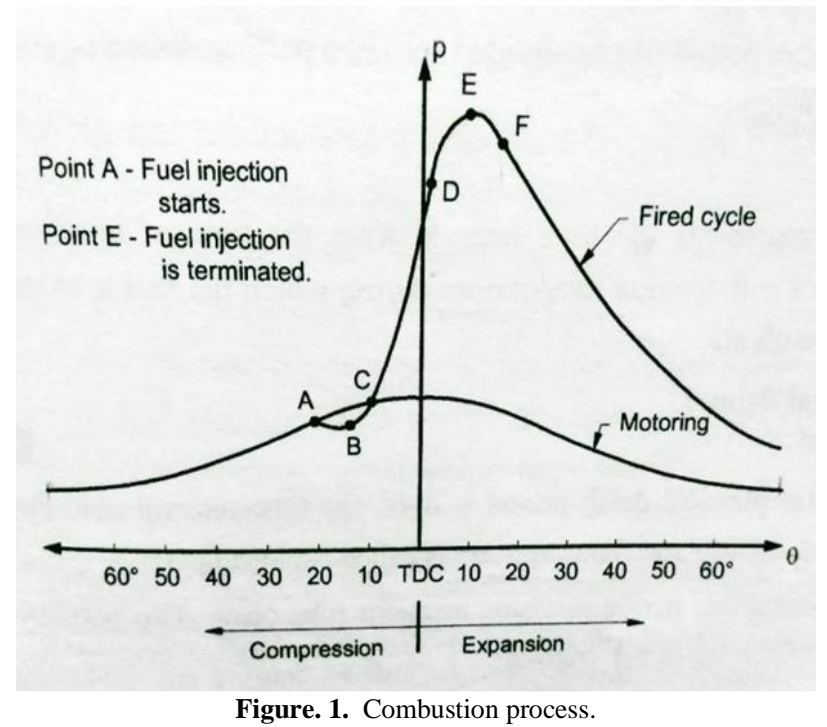

Diesel engines have a high compression ratio because diesel engines have high pressure and temperature to run diesel fuel perfectly. In addition, the quality of diesel fuel can be seen in the combustion system. In addition, Green Diesel fuel is thought to have high performance and high power, but sometimes with high performance, it causes high vibration and enthusiasm as well as a result of the explosion and pressure in the engine combustion chamber. Therefore, this study aims to examine the impact of the performance power of Green Diesel on the impacts and vibrations that occur.

This research will discuss the vibration analysis and diesel motor that uses green diesel fuel compared to using B30 sold by PT Pertamina. It is hoped that the results of the research can be useful as information to prove the effectiveness of these fuels on diesel engines.

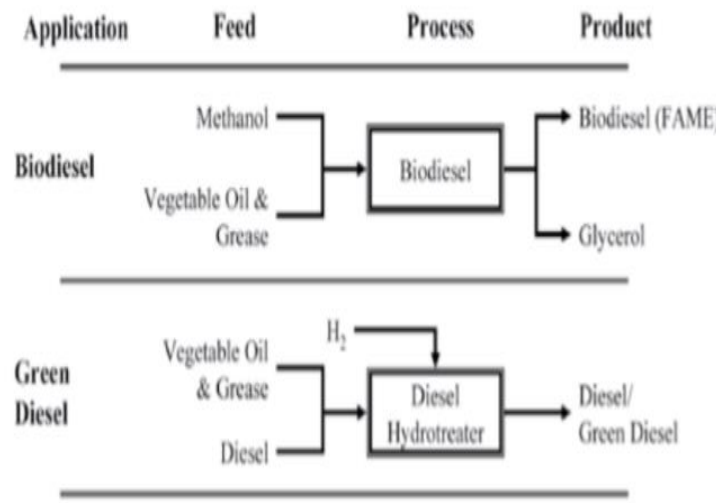

Figure. 2. Differences in the process of making fuel [3].

\section{A. Diesel Engine}

The diesel motor is an internal combustion engine that uses compression to burn the fuel that is injected into the combustion chamber. There is a difference with a gasoline motor in the cycle process, where the fuel from the gasoline motor is ignited by the spark plug, while the diesel motor fuel is ignited by compression, and also the fuel consumed is different. Diesel motors have a high compression ratio so that they have thermal efficiency compared to other internal and external combustion engines. Based on the workings of the diesel motor, it is divided into two, namely 4 stroke and 2 stroke diesel engines. The difference is in the way it works in producing combustion. The 4-stroke diesel engine requires four strokes of the piston or two crankshaft rotations.

\section{B. Combustion Process}

Combustion is a process of a rapid chemical reaction between fuel and air fluids. This process produces an explosion in the combustion chamber. In internal combustion engines, there are several periods or stages of combustion for different engines. In the Compression Ignition Engine, in the compression stroke, only air has been compressed at very high pressures and temperatures. The compression ratio used is in the range of 12 to 120 . The temperature of the air is higher than the temperature of diesel fuel in the CI engine. Then diesel fuel is injected into the combustion chamber under very high pressure of around 120 to 210 bar. Fuel temperature is approximately 20 to 35 degrees before Top Deadline (TDC). The combustion process creates a force due to the rapid pressure of the heat rate arising from combustion. As a result of this force, it causes vibration and noise due to the structure due to the large force acting on the motor which will cause shock or friction which causes vibration and noise [4]. 
There are 4 different stages of combustion as follows: 1. Ignition Delay Period

2. Uncontrolled Burning Period

3. Controlled Burning Period

4. Continued Burning Period

\section{Green Diesel}

The raw material for green diesel fuel is vegetable oil. Not only generated from vegetable oil, but green diesel is also produced from other biomass sources such as animal fat [1].

Renewable diesel or green diesel can be made from the same raw materials as biodiesel because both require materials containing triacylglycerol from biomass. Green diesel blends follow the same nomenclature as biodiesel. Green diesel in its pure form is called "R100" while a mixture consisting of $20 \%$ green diesel and $80 \%$ petrodiesel is called "R20" [5].

Just like biodiesel, green diesel is categorized as a biological product with an impact on the accumulation of carbon dioxide in the atmosphere. In terms of the combustion process, unlike petroleum, it is free from aromatics or naphtha and results in cleaner combustion. Green diesel is non-corrosive, more stable, and has a heat value compared to petroleum diesel because it does not contain oxygen. Another advantage is that it has superior cold-weather behavior compared to biodiesel, and also it does not increase nitrogen oxide emissions and has a higher cetane number so that ignition is easier [1].

The raw materials for Green Diesel and Biodiesel are generally the same, namely from vegetable oil. However, these two fuels produce different fuel content and characteristics due to the manufacturing process. Biodiesel fuel is produced conventionally through a triglyceride transesterification process with the addition of methanol. The reaction is catalyzed to produce FAME and glycerol as by-products [3].

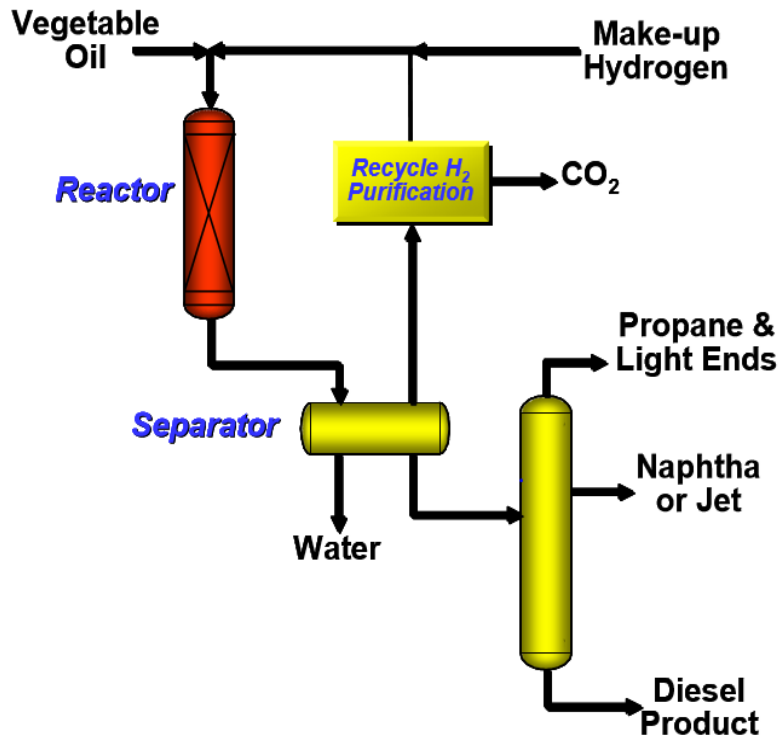

Figure. 3. Green diesel manufacturing technology scheme.

Green Diesel fuel is produced through a hydroprocessing process, using the help of hydrogen gas to remove oxygen from triglyceride molecules. Then, oxygen is removed through two reactions, namely decarboxylation, and hydrodeoxygenation. The rate for each reaction depends on the catalyst and process conditions.

Generally, green diesel fuel can be produced from biomass through four technologies, such as:

A. Hydroprocessing

B. Catalytic upgrading of sugars, starches, and alcohols

C. Thermal conversion (pyrolysis) and upgrading of bio-oil

D. Biomass to liquid (BTL) thermochemical processes

Hydroprocessing is a catalytic process that uses hydrogen to convert triglycerides from biomass oils and fats into saturated hydrocarbons. Chilling process technologies including Aqueous Phase Reforming are used in the catalytic upgrading of sugars, starches, and alcohols (APR). Thermal conversion entails the pyrolysis of biomass and the manufacture of bio-oil, which is then processed into green diesel. Finally, the BTL process involves high-temperature biomass gasification for the processing of Hydrogen and CO-rich syngas, followed by the Fischer-Tropsch (FT) chemical synthesis of liquid green diesel [6].

\section{Vibration}

Vibration is a movement back and forth in a certain time interval. Vibration is assembled by the oscillatory motion of objects and forces associated with motion. All objects having weight and elasticity can vibrate. Most machines and structures experience vibration to some degree and their design usually requires consideration of oscillatory properties.

Vibration is a forward and backward motion or oscillating motion in an object that has the weight and elasticity of the spring weight system [7].

Based on the type of movement, the vibration is divided into two, namely:

1. Rectilinear vibration Objects move up and down or back and forth. 
2. Rotational vibration Moving object rotates.

Based on the Decree of the State Minister for the Environment No. 49 of 1996 concerning Standard Vibration Level states that:

1. Vibration is the movement back and forth of a mass through a state of balance towards a reference point.

2. Mechanical vibrations are vibrations generated by human activity facilities and equipment.

3. Seismic vibrations are ground vibrations caused by natural events and human activities.

4. Shock vibration is a vibration that occurs suddenly and momentarily.

5. Mechanical vibration and shock vibration level standards are the maximum permissible levels of mechanical vibration from a business or activity on solid media so as not to cause disturbances to the comfort and health and integrity of the building.

\section{E. Noise}

Noise is the noise generated from non-periodic vibrations or unwanted sounds. Noise can consciously or unconsciously disrupt the emotional balance. The unit for measuring the value of noise in decibels $(\mathrm{dB})$. The decibel is the smallest unit of the noise level that can be felt by humans. Noise is avoided by humans because it can interfere with concentration at the moment. Noise besides having a bad impact on humans, noise can also harm the surrounding environment. The noise value levels are: (30 dB: weak whispering voice); ( $85 \mathrm{~dB}$ : safe limit, ear protection is recommended); (90 dB: can damage hearing within 8 hours, for example, the sound of lawnmowers, the sound of a truck on a traffic jam); (100 dB: damage hearing within 2 hours, for example, chainsaw sound, voice over the telephone); (105 dB: damage hearing within 1 hour, for example, helicopter sound, stone breaking machine sound); (115 dB: damage hearing within 15 minutes, for example, baby crying, boisterous noise in a football stadium $) ;(120 \mathrm{~dB}$ : damage hearing in 7.5 minutes, for example, rock concert sound); (125 dB: pain threshold in the inner ear, for example, the sound of firecrackers and sirens); (140 dB: endanger hearing in a short time, for example, gunshots and jet engines) [8].

The noise that is identical to the annoying sound can have a negative impact. The impact of noise, in general, can be categorized into two based on the level of noise intensity and the length of time of exposure, among others, are as follows:

1) High-intensity noise impacts

a. Generally, it causes damage to the sense of hearing which can cause hearing loss, both temporary and permanent, or deafness.

b. Physiologically, high-intensity noise can cause health problems such as increased blood pressure and heart pressure, increased risk of heart attack, and indigestion.

c. The emotional reaction of the community, if the noise from a production process is so great that the surrounding community demands that the activity be stopped.

2) Low-intensity noise impact

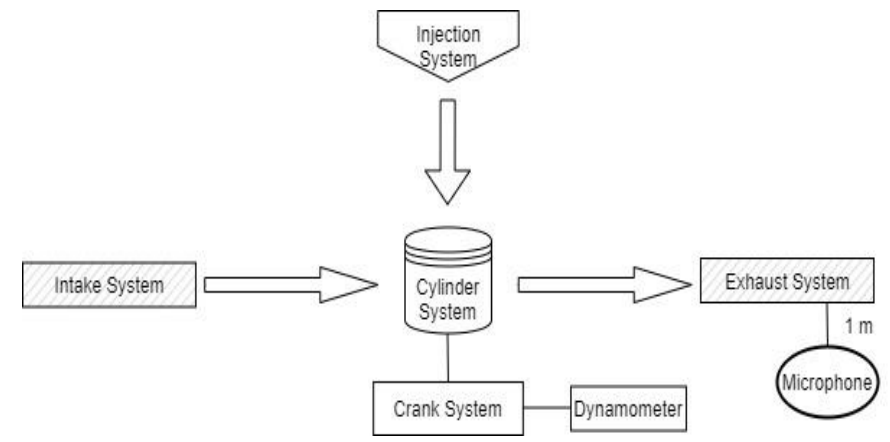

Figure. 4. Noise simulation model.

Low noise intensity levels are commonly found in work environments such as offices, corporate administration rooms, and others. Low-intensity noise does not cause hearing damage physiologically. However, their presence can often cause:

a. The decrease in work performance, which can cause loss of work efficiency and productivity.

b. As a cause of stress and other health problems. The stress caused by noise can lead to premature fatigue, anxiety, and depression. It can also cause irritability, headaches, and sleep disorders.

c. Psychomotor reaction disorders and loss of concentration.

d. Tinnitus is a ringing sound in the ear that often appears suddenly. Although the ringing will disappear within a few hours, it can be used as an indicator of hearing damage. 


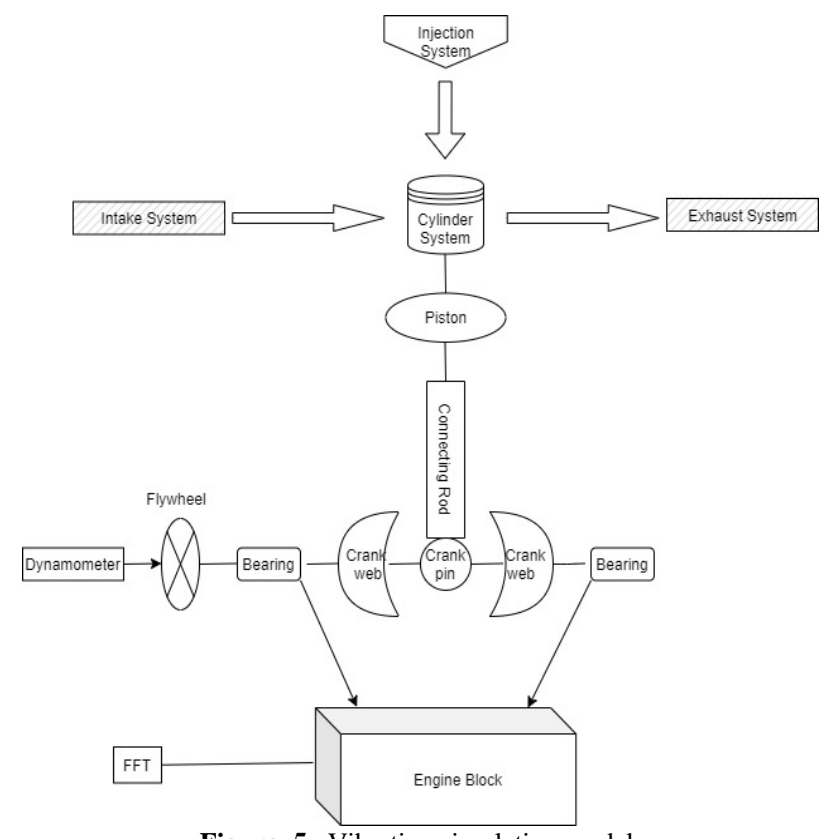

Figure. 5. Vibration simulation model.

\section{METHOD}

This study using a simulation method. In completing this research, there are 3 main stages in carrying out the research process which will be explained as follows:

A. Green Diesel Properties
The manufacture of Green Diesel uses a hydrotreating process. To find out the properties of Green Diesel fuel by reading the journal to get the following fuel content data parameters to be entered into the simulation software. The following table 1 . contains the content of Green Diesel fuel.

TABLE 1.

GREEN DIESEL FUEL CONTENT [1]

\begin{tabular}{cccc}
\hline No & Content & Unit & Value \\
\hline 1 & Carbon (wt\%) & - & 84.9 \\
2 & Hydrogen (wt\%) & - & 15.1 \\
3 & Oxygen(wt\%) & - & 0.0 \\
4 & Cetane Number (CN) & - & $>70$ \\
5 & Lower Heating Value & $\mathrm{MJ} / \mathrm{Kg}$ & $43.7-44.5$ \\
6 & Density at 150c & $\mathrm{Kg} / \mathrm{m} 3$ & $770-790$ \\
7 & Polycyclic Aromatic Hydrocarbons (wt\%) & $<0.1$ \\
8 & Sulfur Content & $\mathrm{Mg} / \mathrm{Kg}$ & $<5$ \\
9 & Flash Point & $\mathrm{C}$ & $>59$ \\
10 & Ash Content(wt\%) & $<0.001$ \\
11 & Water Content(mg/kg) & $\mathrm{Mg} / \mathrm{Kg}$ & $<200$ \\
\hline
\end{tabular}

\section{B. Engine Set-Up}

Making a simulation model retrieves engine noise and vibration data in software using a Yanmar TF85 $\mathrm{MH}$ engine adjusted to engine specification data.

In the simulation model, the noise analysis requires a component in the form of a microphone. Noise data is taken at a distance of $1 \mathrm{~m}$ from the sound source.

Measurement of machine noise is carried out at the conditions of RPM 1600,1700,1800, 1900, 2000, 2100 and 2200 with a load variation of $40 \%, 50 \%, 60 \%, 70 \%$, $80 \%, 90 \%, 100 \%$.
Measurements using FFT by attaching a vibration sensor to the engine block to be measured, then it will be converted into a graph of the vibration amplitude that occurs in the engine block. The data received by the FFT on the engine block is in the form of displacement (micrometer).

Measurements are made using variations of RPM at constant load (Full Load), namely RPM 1600, 1700, 1800, 1900, 2000, 2100, and 2200. 


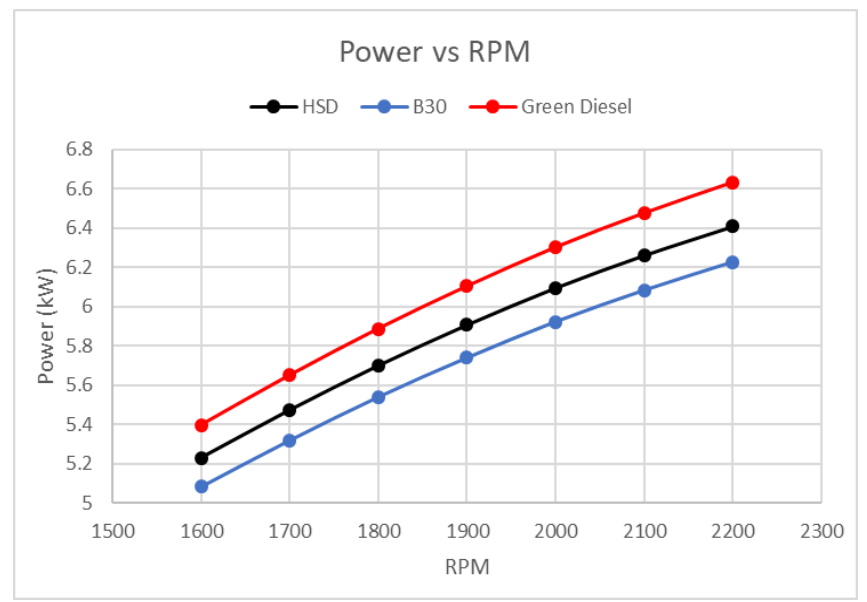

Figure. 6. Power graph at full load condition.

\section{Model Calibration}

After modeling the Yanmar TF85 - MH diesel engine. The calibration process is carried out to obtain data or simulation performance results that are following the engine maker provided in the Yanmar TF85 - MH catalog.

There are some data needed to perform machine calibration, namely:

a. Fuel content

b. Yanmar TF85 engine component size data

c. Yanmar TF85 engine catalog

d. And other supporting data.

Calibration is carried out at $2 \mathrm{RPM}$ points as a benchmark. For 2200 RPM the power and SFOC were calibrated. As for the 1600 RPM, the torque is calibrated. The calibration uses 2combust (HSD) diesel fuel and the following error results are obtained:

From table 2. below, the simulation results show the power of $8.59 \mathrm{HP}$ and SFOC $171.38 \mathrm{~g} / \mathrm{HP}-\mathrm{h}$. When compared with the engine catalog in the figure where the power is $8.5 \mathrm{HP}$ and SFOC is $171 \mathrm{~g} / \mathrm{HP}-\mathrm{h}$, the error difference is $1.04 \%$ for power and $0.22 \%$ for SFOC.

From table 3 . below the simulation results show a torque of $3.21 \mathrm{kgf}-\mathrm{m}$. When compared with the engine catalog in the figure where the torque is $3.4 \mathrm{kgf}-\mathrm{m}$, the error difference is $5.5 \%$.

\section{RESULT AND DISCUSSION}

After taking noise and vibration data through simulation. The results of the data were analyzed and discussed to obtain conclusions from the research conducted.

\section{A. Power Graph Full Load Condition}

The power generated from the 3 types of fuel shows the difference in the power produced by the engine. Whereat the highest RPM, namely RPM 2200, Green Diesel fuel has a power of $6.63 \mathrm{~kW}$, Biodiesel B30 has a power of $6.22 \mathrm{~kW}$, and HSD fuel has a power of 6,411 $\mathrm{kW}$.

TABLE 2.

SIMULATION RESULTS OF RPM 2200

\begin{tabular}{lll} 
& \multicolumn{3}{c}{ Calibration } & Manual book \\
\hline Power $(\mathrm{HP})$ & 8.59 & 8.5 \\
Power $(\mathrm{kW})$ & 6.41 & 6.33 \\
Torque $(\mathrm{kgf}-\mathrm{m})$ & - & - \\
SFOC $(\mathrm{g} / \mathrm{HP}-\mathrm{h})$ & 171.38 & 171 \\
\hline
\end{tabular}

When the RPM or engine rotation speed increases, the resultant power generated by the engine also increases. This is proportional to the higher the pressure and explosion of combustion in the combustion chamber.
The conclusion is that Green Diesel fuel has higher power at every engine RPM, and Biodiesel B30 fuel has lower power when compared to Green Diesel and HSD.

TABLE 3.

SIMULATION RESULT RPM 1600

\begin{tabular}{ccc}
\multicolumn{3}{c}{ SIMULATION RESULT RPM 1600 } \\
\hline & Calibration & Manual book \\
\hline Power (HP) & - & - \\
Power $(\mathrm{kW})$ & - & - \\
Torque $(\mathrm{kgf}-\mathrm{m})$ & 3.21 & 3.4 \\
SFOC $(\mathrm{g} / \mathrm{HP}-\mathrm{h})$ & - & - \\
\hline
\end{tabular}




\section{B. Noise Level}

In this simulation, a noise level test is carried out on a diesel engine using Green Diesel and Biodiesel B30 as fuel. Data obtained in the form of Sound Pressure Level (SPL). SPL shows how much change in pressure is experienced by the medium from its equilibrium condition.

In this study, the RPM variables used were 1600, $1700,1800,1900,2000,2100,2200$ by showing the SPL graph for each and being compared with the two fuels tested.

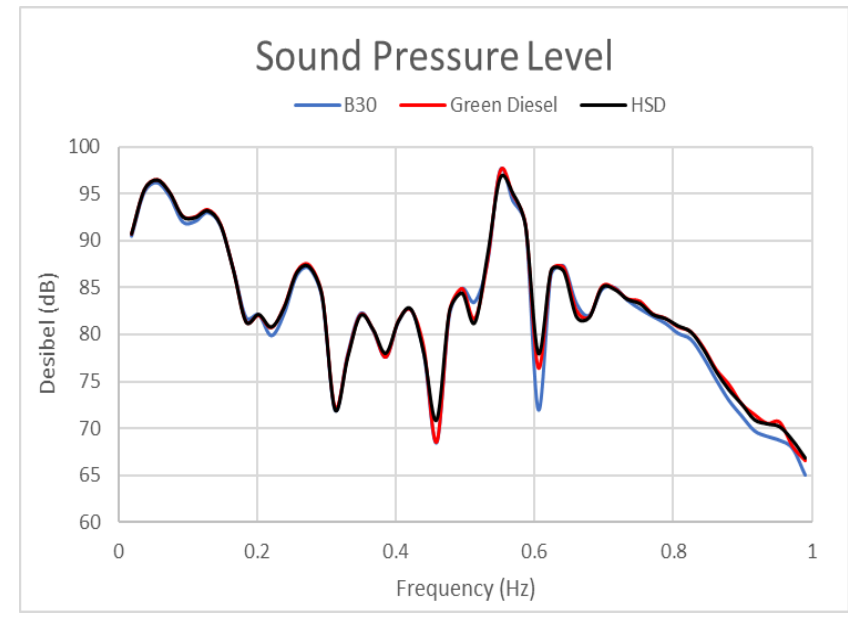

Figure. 7. Graph of sound pressure level at $2200 \mathrm{rpm}$ full load.

In figure 7. above, we can see a comparison of the noise level at 2200 RPM Full Load conditions between Green Diesel, HSD, and Biodiesel B30. The noise from Green Diesel fuel is higher than HSD fuel and Biodiesel B30 fuel. At a frequency of $0.1 \mathrm{kHz}$, Green Diesel fuel has a noise of $93.29 \mathrm{~dB}$. For HSD fuel at a frequency of $0.1 \mathrm{kHz}$, it has a noise of $93.19 \mathrm{~dB}$. Biodiesel B30 fuel at a frequency of $0.1 \mathrm{kHz}$ has a noise of $92.99 \mathrm{~dB}$. A comparison of the value of the noise that occurs is directly proportional to the power generated by each fuel. Where the Green Diesel fuel has higher power than HSD fuel and Biodiesel B30 and also the pressure in the combustion chamber is higher. The higher the pressure and the explosion in the combustion process will result in higher noise as well.

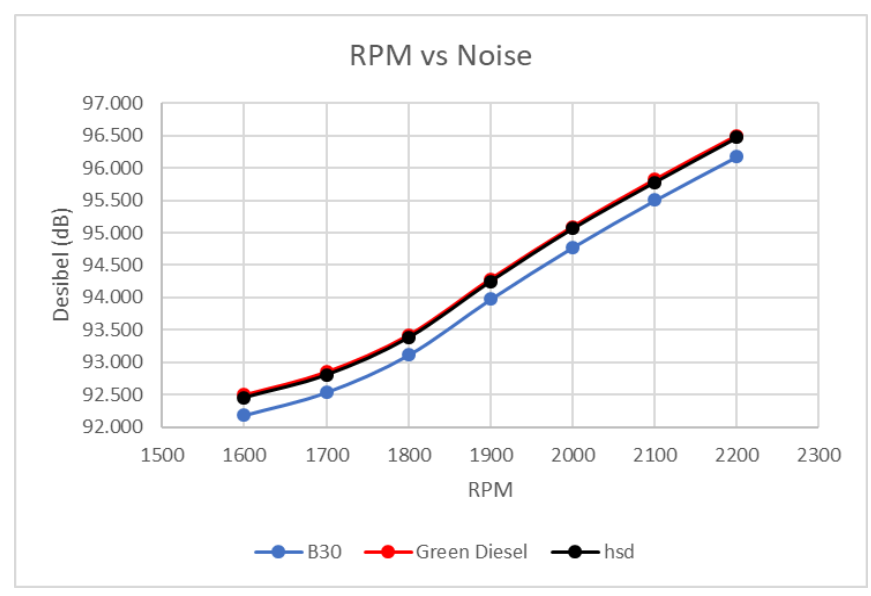

Figure. 8. RPM vs noise noise graph.

In figure 8 . above, we can see a comparison of the noise level against the RPM or engine rotation speed. Green Diesel fuel has a higher noise than HSD fuel and Biodiesel B30. Increasing the speed of the engine will increase the demand for fuel. This happens with increasing speed so it requires more energy and causes a bigger explosion. The combustion process creates pressure in the cylinder which has an impact on the noise produced by the engine. It can be seen that the increase in the engine rotation speed has an impact on the increase in engine noise.

The conclusion that can be drawn by increasing the rotation speed, the engine has an increase in work. The increase in work will increase the amount of fuel that enters the cylinder. Increasing the amount of fuel increases the pressure in the combustion process. The higher pressure and explosion in the combustion chamber make the parts inside the engine rub against and vibrate causing noise

In figure 9., we can see the comparison of the noise level at 2200 RPM with a load of $100 \%$ between Green Diesel fuel, HSD, and Biodiesel B30. The noise from Green Diesel fuel is higher than HSD fuel and Biodiesel B30 fuel. At a frequency of $0.05 \mathrm{kHz}$, Green Diesel fuel has a noise of $96,474 \mathrm{~dB}$. For HSD fuel at a frequency of $0.05 \mathrm{kHz}$, it has a noise of 96,442 dB. For Biodiesel B30 
fuel at a frequency of $0.05 \mathrm{kHz}$, it has a noise of 96,162 $\mathrm{dB}$. A comparison of the value of the noise that occurs is directly proportional to the power generated by each fuel. Where the Green Diesel fuel has higher power than
HSD fuel and Biodiesel B30 and also the pressure in the combustion chamber is higher. The higher the pressure and the explosion in the combustion process will result in higher noise as well.

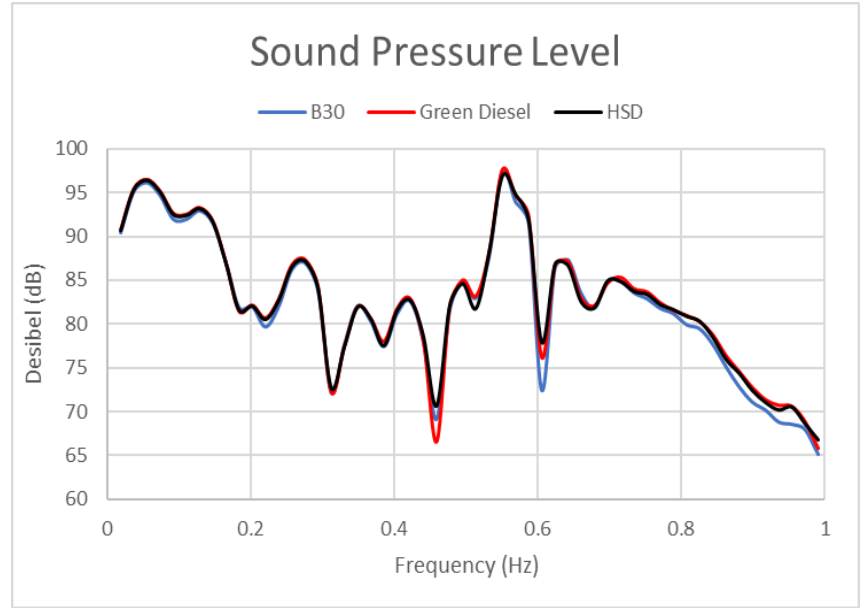

Figure. 9. Graph of sound pressure level at $100 \%$ load RPM.

In figure 10, it can be seen the comparison of the noise level of 2200 RPM using load variations. Green Diesel fuel has a higher noise than HSD fuel and Biodiesel B30. It can be seen that the engine noise using
Green Diesel fuel tends to decrease when given loading. As for the engine noise that uses B30 fuel, the noise changes are more stable than Green Diesel fuel when loaded.

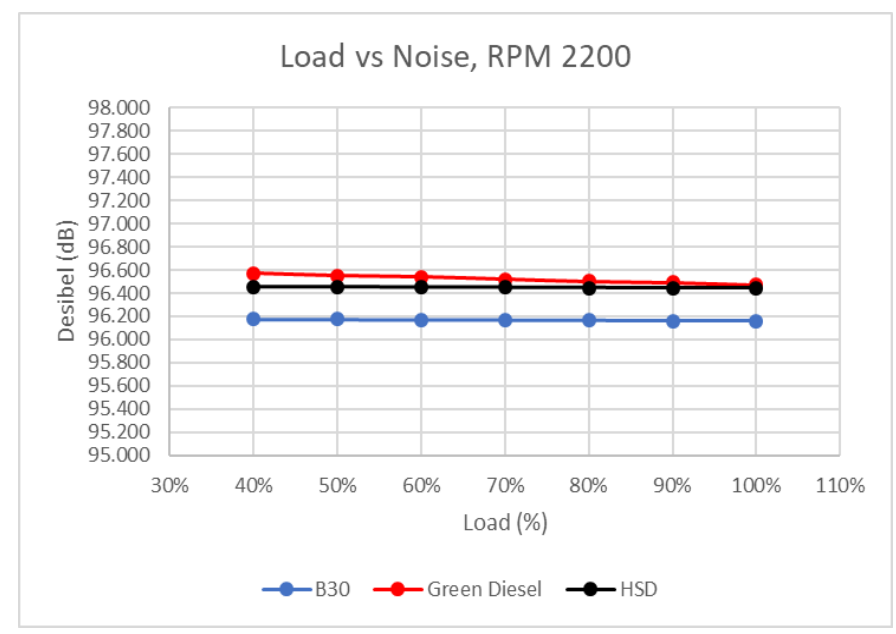

Figure. 10. Graph of sound pressure level at 100\% load RPM.

Green Diesel fuel has the lowest noise point at 96.47 $\mathrm{dB}$ at $100 \%$ load conditions at 2200 RPM. While HSD fuel has the lowest noise at $100 \%$ load of $96,422 \mathrm{~dB}$ and Biodiesel B30 fuel has the lowest noise point, namely $96,162 \mathrm{~dB}$ at load $100 \%$. It can be seen that HSD fuel and Biodiesel B30 did not experience a significant change when given a different loading from Green Diesel fuel which experienced a significant decrease when given loading.

C. Vibration Level
In this simulation, a vibration level test is carried out on a diesel engine using Green Diesel and Biodiesel B30 as fuel. As well as adding HSD fuel as supporting data. By using the FFT component in the simulation.

In this research, the RPM variables used are 1600, $1700,1800,1900,2000,2100,2200$ by showing a graph of the respective vibration amplitudes and comparing them with the three fuels that have been tested. The placement is placed on the engine block. The input data read by the sensor is in the form of a display (micrometer) which is then converted into an 'Amplitude vs Frequency' graph. 


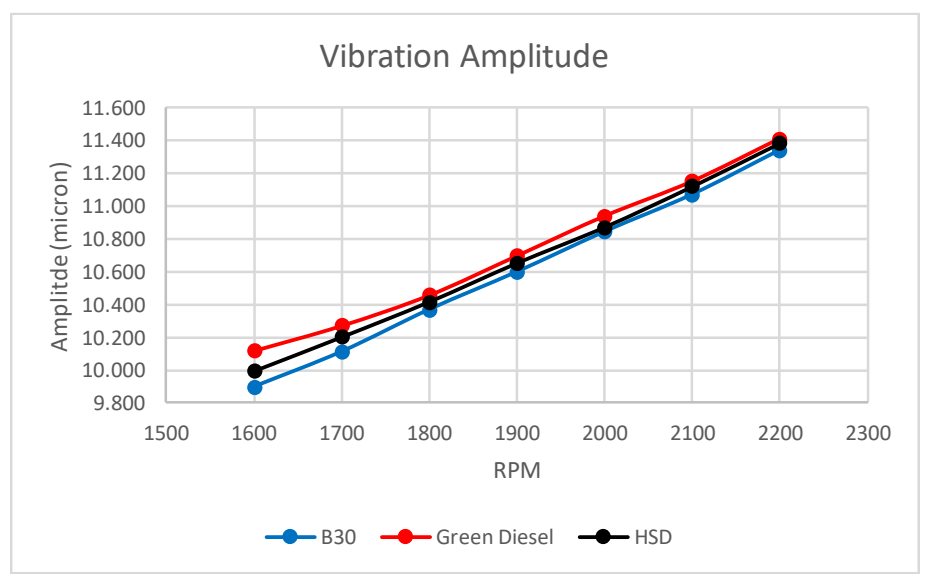

Figure. 11. RPM vs amplitude vibration comparison graph.

In figure 11. above, we can see the comparison of the level of vibration to the RPM or engine rotation speed. Green Diesel fuel has higher vibrations compared to HSD fuel and Biodiesel B30. It can be seen that the higher the RPM or the engine rotation speed, the higher the vibration.

Green Diesel fuel has the highest vibrational amplitude at 2200 RPM of 11.41 micrometers and Biodiesel B30 fuel of 11,343 micrometers and HSD fuel at 11,385 micrometers.

\section{Discussion Analysis}

From the simulation analysis results, the use of Green Diesel fuel has a higher noise and vibration level than HSD fuel and Biodiesel B30.

According to research conducted [9], the noise in a diesel engine comes from burning fuel in the cylinder. Combustion will produce pressure and an explosion that makes diesel engine parts rub against, vibrate and move, causing the noise.

The high power of Green Diesel fuel makes the pressure and explosion in the combustion chamber high too when compared to HSD fuel and Biodiesel B30 which has lower power and pressure in the combustion chamber

The noise and vibration levels are strongly influenced by the combustion process and the movement of the components in the fire chamber. With increasing rotation, the engine increases its performance. The increase in work will increase the amount of fuel entering the cylinder and require more pressure to carry out the combustion process.

Increasing the pressure required for the combustion process will increase the vibration in the engine. The increased vibration results in increased noise as well as a result of the explosion and friction of components in the combustion chamber. Because basically sound is a vibration that moves and is received by the ear [4].

\section{CONCLUSION}

By simulating and analyzing the data from the experiment, the following conclusions can be drawn:

1) Effect of Green Diesel fuel on diesel engine noise and vibration: a. Green Diesel fuel has increased noise levels in accordance with the increase in engine rotation speed or RPM. Where the highest noise is generated at 2200 RPM of 96,495 dB.

b. Green Diesel fuel experiences an increase in the level of vibration according to the increase in rotation speed or engine RPM. The highest vibration occurred at 2200 RPM under the full load of 11,412 micrometers

2) Effect of Biodiesel B30 fuel on diesel engine noise and vibration:

a. Biodiesel fuel B30 has increased noise levels in accordance with the increase in engine rotation speed or RPM. Where the highest noise is generated at $2200 \mathrm{RPM}$ of $96,177 \mathrm{~dB}$.

b. Biodiesel fuel B30 has an increase in the level of vibration according to the increase in rotation speed or engine RPM. The highest vibration occurred at 2200 RPM under the full load of 11,343 micrometers.

3) The results of the comparison of noise and vibration produced by Green Diesel fuel and Biodiesel B30 are as follows:

a. Green Diesel fuel noise has increased by $0.33 \%$ from Biodiesel B30 fuel

b. The vibration of Green Diesel fuel has an increase of $0.6 \%$ from Biodiesel B30 fuel

\section{REFERENCES}

[1] Douvartzides, S. L., Charisiou, N. N., N. , K. P. \& Goula, M. A., 2019. Green Diesel: Biomass Feedstocks, Production Technologies, Catalytic Research, Fuel Properties and Performance in Compression Ignition Internal Combustion Engines. Energies 2019, 12, 809; doi:10.3390/en12050809.

[2] Yildirim, H., Ozsezen, A. N. \& Cinar, A., 2018. Vibration and Noise Depending upon Engine Speed in a Diesel Engine Fueled with Biodiesel.

[3] Piemonte, V., 2019. Green Diesel. Rome: University UCMB.

[4] Arif, S., 2004. Analisa Getaran Dan Kebisingan Pada Motor Diesel. Surabaya: Institut Teknologi Sepuluh Nopember.

[5] Yoon, J. J., 2019. What's the Difference between Biodiesel and Renewable (Green) Diesel.

[6] Srifa, A. et al., 2014. Production of bio-hydrogenated diesel by catalytic hydrotreating of palm oil over NiMoS $2 / \gamma-\mathrm{A} 12 \mathrm{O} 3$ catalyst. Bioresour.Technol.

[7] Hidayat, R., 2017. ANALISIS GETARAN PADA KOMPRESOR MESIN PENDINGIN DENGAN VARIASI PUTARAN (RPM) Volume 15 no. 2 Oktober 2017. 
International Journal of Marine Engineering Innovation and Research, Vol. 6(1), Mar. 2021. 77-86

(pISSN: 2541-5972, eISSN: 2548-1479)

[8] Annur, M. N., 2019. PENGARUH PEMANASAN BAHAN BAKAR B20 DAN B30 TERHADAP NOISE MESIN DIESEL SINGLE SILINDER, Surabaya: Tugas Akhir. Departemen Teknik Sistem Perkapalan. F.T. Kelautan. Institut Teknologi Sepuluh Nopember.
[9] Khan, S. A., 2019. Investigation of Noise and Vibration Levels in CI Engine using Diesel Investigation using Diesel and Jatropha Diesel. 